\title{
FORMULATION AND EVALUATION OF EFFERVESCENT GASTRO-RETENTIVE FLOATING TABLETS FOR CON- TROLLED RELEASE OF AN ANTI-ULCER COMPOUND
}

\author{
Aleksandar Aleksovski ${ }^{1}$ \\ Emina Zahirović \\ Amra Demirović \\ Emilija Spaseska Aleksovska
}

Original scientific paper

ZADA Pharmaceuticals, Bistarac Donji bb, 75300 Lukavac, Bosnia and Herzegovina

Received: 29.06 .2012

Accepted: 23.08.2012

UDC 615.015 .15

615.24.015.15

\begin{abstract}
Effervescent floating gastro-retentive matrix tablets present novel and promising approach towards targeted and controlled drug delivery in the stomach and in the upper part of the small intestine. This kind of dosage form could be obtained by combining in a suitable ratio effervescent compounds and hydrophilic/hydrophobic polymer/s. The aim of our investigation was to develop controlled release effervescent matrix tablet which will float over the gastric media for longer than 8 hours and will release the active compound in a continuous manner over 8 hours period. We used ranitidine $\mathrm{HCl}$ as a model drug which has narrow absorption window in the upper small intestine, and is a good candidate for this type of dosage forms. We employed sodium bicarbonate and citric acid as effervescent compounds and two different types of hydroxypropyl methylcellulose (HPMC K4M and HPMC K15M) as a controlled release hydrophilic polymer. Three batches of tablets were produced (one containing HPMC K4M, other containing HPMC K15M, and the third containing 1:1 mixture of these two polymers) and every batch was compressed with two different forces $5.5 \mathrm{kN}$ and $4.7 \mathrm{kN}$, so completely six probes of tablets were made. All six probes complied the pharmacopoeial requirements concerning mass uniformity, content, friability and hardness. All six probes tended to float fast to the surface of the medium and tend to hydrate and swell fast enough which actions provided controlled release of the compound over period of 8 hours. No significant differences in the dissolution profiles of all six probes were noticed during the investigation.
\end{abstract}

Keywords: gastro-retentive, controlled release, effervescent, hydrophilic polymer, floating, swelling

\section{INTRODUCTION}

Oral drug administration is still the most common and most popular pathway of medical application due to several advantages such as: ease administration, less invasive treatment and greater patient's compliance. In terms of ameliorating the therapeutic outcome, minimizing side effects and increasing patient's compliance scientists pay huge attention on developing oral controlled (extended) release dosage forms which will deliver the active compound in a controlled fashion over longer periods of time (Qui et al, 2008).

${ }^{1}$ Correspodence to:

Aleksandar Aleksovski, ZADA Pharmaceuicals

Bistarac donji bb, 75300 Lukavac, B\&H

Phone: 0038970735642

E-mail: aleksandar.a@zada.ba; acko_aleks@yahoo.com 
Controlled release dosage forms (tablets and capsules) provide many advantages over conventional solid dosage forms such as: lower incidence of drug concentration fluctuations in both the plasma and on the site of action, lower incidents of side effects, decreased dosage regime etc. Controlled release dosage forms could be designed as mono- or multi-dosage units in a form of: matrix systems (hydrophilic or lipophilic), membrane systems, osmotic systems (Aulton, 2007). Conventional oral controlled release dosage forms may not be suitable for some active substances, such as those which demonstrate changeable solubility at different $\mathrm{pH}$ values, those which do not provide uniform absorption through whole GUT, compounds which show instability at certain region of the GUT (Wilson \& Crovley, 2011). These aspects led scientists into research and development of novel targeted controlled release oral dosage forms. One of the approaches towards targeted oral therapy is gastric retention of solid dosage form. Gastro-retentive solid dosage forms are kept in the stomach for prolonged period of time, providing controlled release of the active substance in this region while resisting gastric motion and emptying sequences (Wilson \& Crovley, 2011). Gastric retention is beneficial for active compounds which have narrow absorption window in the upper parts of the GUT (stomach or duodenum) such as riboflavin and levodopa; active compound which act locally in the stomach (some antacids); compounds which are unstable or have low solubility in alkaline media and compound which may be harmful for the micro-flora of the small intestine or the colon (Nirav, 2011, pp. 571-580).

Many techniques for gastric retention are developed and one of the quite successful techniques is the production of effervescent hydrophilic matrix systems (mostly tablets)

Effervescent hydrophilic matrix tablets are composed of hydrophilic polymers (hydroxypropyl methylcellulose, hydroxyethyl cellulose, hydroxpropyl cellulose, polyethylene oxide, chitosan, alginate, guar gum, xantan gum, acacia etc.) and effervescent components such as sodium bicarbonate/sodium carbonate with or without citric/tartaric acid in combination $(\mathrm{Ku}-$ mar et al, 2011, pp. 423-436). The controlled release of the active compound is based on dif- fusion and erosion and it is due to the capability of the outer part of the hydrophilic matrix to hydrate and swell in contact with the gastric media which leads in formation of outer hydrated porous gel layer (Dwivedi \& Kumar, 2011, pp. 1413-1426). The gastric media could easily penetrate into this porous gel layer and to dissolve the active compound which then leaves the matrix by diffusion through the gel layer pores. When the outer layer is completely hydrated it starts to erode and it is replaced by new polymer layer which undergoes continuous hydration. By erosion additional amounts of active substance is delivered to the media. In contact with gastric fluids effervescent matrix tablets exhibit in-situ effervescent reaction which leads to $\mathrm{CO} 2$ formation, which $\mathrm{CO} 2$ is entrapped into the hydrated and swelled polymer layer. All these actions lead to decrease in system's bulk density and buoyancy over the gastric content (Aleksovski, 2012, pp. 23-30).

Ranitidine is reversible, competitive inhibitor of histamine $\mathrm{H}-2$ receptors. It is used in the treatment of peptic gastric and duodenal ulcers, gastro-esophageal reflux disease, Zollinger-Ellison syndrome and corrosive esophageal disease. It is known that the conventional ranitidine dose of $150 \mathrm{mg}$ inhibits the gastric secretion up to 5 hours but not up to 10 hours. On the other hand the dose of $300 \mathrm{mg}$ shows fluctuating drug levels in the plasma (Reynolds, 1996). Due to the narrow absorption window in the upper small intestine ranitidine is suitable candidate for development of effervescent hydrophilic matrix tablets.

Hydroxypropyl methylcellulose (HPMC) is very frequently used hydrophilic polymer in the production of controlled release matrix tablets, due to its inert nature, $\mathrm{pH}$-independency, suitable flowability and compressibility and safety (Wen \& Park, 2010). High viscosity HPMC grades tend to be most suitable candidates for controlled release matrix preparation due to the fast hydration and gel layer formation which provide continuous release of the active compound (by diffusion and erosion) and maintenance of tablet integrity. Combination of HPMC-s with different viscosity grade usually provide modification of the rate and extent of drug release (usually and intermediate drug release is obtained) (Aleksovski et al, 2012, pp. 22-31). 


\section{MATERIALS AND METHODS}

\section{Used Materials}

Ranitidine $\mathrm{HCl}$ (Orchev Pharma PVD LTD, India); Methocel K4M ${ }^{\circledR}$ (HPMC with viscosity 4000mPa.s,) and Methocel K15M® (HPMC with viscosity $15000 \mathrm{mPa} . \mathrm{s})$ (Colorcon $\left.{ }^{\circledR}, \mathrm{UK}\right)$. Sodium bicarbonate, citric acid and talc (MERCK, Germany); Microcrystalline cellulose (MCC) (JRS PHARMA GmbH KG, Germany); Copovidone (BASF, Germany); Magnesium stearate (Dr. Paul Lohmnann GmbH KG, Germany). All other ingredients, solvents end reagents were with analytical grade.

\section{Methods}

\section{Evaluation of powder mixture}

All powder compounds (except magnesium stearate) were accurately weighted, passed through standard sieve $0.8 \mathrm{~mm}$ and mixed thoroughly for 5 minute. After sieving powder mixture was evaluated for bulk density and tapped density (PhEur 7), Carr's index and Hausner ratio and angle of repose (standard funnel and petri dish with radius of $4.75 \mathrm{~cm}$ ).

\section{Tablet production}

After mixing powder compounds, $\mathrm{Mg}$ stearate was added to the powder mixture by passing it through a standard $0.8 \mathrm{~mm}$ sieve. Powder mixture containing $\mathrm{Mg}$ stearate was thoroughly mixed for period of 1 minute. Floating matrix tablets were produced by direct compression using FETTE 1200 rotary tablet press. Three batches of caplet $14 \mathrm{~mm} \times 7 \mathrm{~mm}$ white-yellowish tablets with mass around $400 \mathrm{mg}$ were produced. Each batch was made with two different compression forces $5.5 \mathrm{kN}(\mathrm{P} 1 / 1, \mathrm{P} 2 / 1, \mathrm{P} 3 / 1)$ and $4.7 \mathrm{kN}(\mathrm{P} 1 / 2, \mathrm{P} 2 / 2, \mathrm{P} 3 / 2)$. Complete composition of formulations $\mathrm{P} 1, \mathrm{P} 2$ and $\mathrm{P} 3(\mathrm{mg})$ is shown in Table 1.

Table 1. Composition (mg) of P1, P2, P3 batch of tablets

\begin{tabular}{|c|c|c|c|c|}
\hline Compound & P1 & $\mathrm{P} 2$ & P3 & Role \\
\hline Ranitidine $\mathrm{HCl}$ & 168 & 168 & 168 & $\begin{array}{l}\text { Active } \\
\text { compound }\end{array}$ \\
\hline HPMC K4M® & 120 & / & 60 & $\begin{array}{l}\text { Hydrophilic } \\
\text { polymer }\end{array}$ \\
\hline HPMC K15M® & / & 120 & 60 & $\begin{array}{l}\text { Hydrophilic } \\
\text { polymer }\end{array}$ \\
\hline Sodium bicarbonate & 50 & 50 & 50 & $\begin{array}{l}\text { Effervescent } \\
\text { compound }\end{array}$ \\
\hline Citric acid & 10 & 10 & 10 & $\begin{array}{l}\text { Effervescent } \\
\text { compound }\end{array}$ \\
\hline $\mathrm{MCC}$ & 32 & 32 & 32 & Diluent \\
\hline Copovidone & 12 & 12 & 12 & Dry binder \\
\hline Magnesium stearate & 4 & 4 & 4 & Lubricant \\
\hline Talc & 4 & 4 & 4 & Lubricant/glidant \\
\hline$\Sigma$ & 400 & 400 & 400 & \\
\hline
\end{tabular}




\section{Evaluation of the produced tablets}

Tablets were evaluated regarding mass uniformity (Mettler Toledo balance), resistance to crushing (Varian VK 200), friability (Varian dual roche type drums), estimation of drug content (Agilent technology 1200 RRLC, VWD detector). Dissolution test was made in accordance with USP (paddle apparatus Varian VK7025), 75rpm speed, in simulated gastric fluid (USP) at temperature of $37^{\circ} \mathrm{C}$. The released amount $(\%)$ of active substance was measured in the intervals of $1,2,4,6$, and 8 hours and determined by UV/VIS Spectrophotometer (Thermo Finigan Evolution 300) at wave length of $313 \mathrm{~nm}$, with a dissolution medium in the reference cell.

In vitro buoyancy studies and swelling index

Randomly selected tablets from all three batches and with two different hardness values were placed in a $100 \mathrm{ml}$ beaker containing simulated gastric fluid (USP) at $37^{\circ} \mathrm{C}$. The time required for tablets to raise and settle on the media's surface was measured and was named as floating lag time (FLT). Floating period of the tablets was examined through time interval of 8 hours. The period through which tablet remained on the media's surface referred as total floating time (TFT). The swelling index of the tablets was determined in $100 \mathrm{ml}$ simulated gastric fluid (USP) at $37^{\circ} \mathrm{C}$ in 1 hour intervals in total period of 8 hours. After each hour tablets were withdrawn from the media, the excess liquid was removed by using filter paper, and the tablets were weighted. Swelling index was determined using the following equation:

$S I(\%)=$ (mass of tablet after certain time(h) - initial mass of tablet)*100/ initial mass of tablet

\section{RESULTS AND DISCUSSION}

\section{Powder and tablet properties}

Concerning powder properties it could be concluded that all three powder mixtures demonstrated similar and relatively good powder flowability, which could be noted from the results for Carr's index (CI), Hausner ratio (HR) and angle of repose (AR). Namely powders having values for $\mathrm{CI}<21 \%, \mathrm{HR}<1.26$ and $\mathrm{AR}$ $<36^{\circ}$ tend to have fair flow and no addition of flow aid compounds is required. The complete results for powder properties are given in Table 2 .

Table 2. Properties of $P 1, P 2$ and $P 3$ powder mixtures

\begin{tabular}{cccc}
\hline Propertie & P1 & P2 & P3 \\
\hline Bulk density $(\mathbf{g} / \mathbf{m l})$ & 0.568 & 0.570 & 0.579 \\
Tapped density $(\mathbf{g} / \mathbf{m l})$ & 0.714 & 0.714 & 0.727 \\
Carr's index $(\%)$ & 20.45 & 20.17 & 20.35 \\
Hausner ratio & 1.257 & 1.252 & 1.256 \\
Angle of repose $\left(^{\circ}\right)$ & 35.86 & 34.87 & 35.01 \\
\hline
\end{tabular}

In terms of pharmacopoeial demands it could be concluded that the examined tablets (from all three batches in both hardness values- in continuation six probes) comply the requirements. Concerning mass uniformity all six probes showed satisfactory results since none of the average masses didn't vary for more than $5 \%$ of the desired mass $(400 \mathrm{mg})$ and also none of the examined tablets didn't have mass variation of $\pm 5 \%$. Concerning drug content all six probes proved to comply the pharmacopoeial requirement of not more than $\pm 5 \%$ of the declared content. In terms of friability all six probes showed values lower than $1 \%$, which is in accordance with the current pharmacopoeias. 
No significant difference in friability values between tablets consisting of different polymer and compressed at same force was noticed. It could be noted that tablets containing the same polymer/polymer blend have slightly different friability values. Namely tablets compressed with larger force tend to have slightly lower friability compared with the ones compressed with smaller force. This could be due to the increased hardness of the tablets and increased binding ability of HPMC when compressed under higher forces. When observing tablets containing the same polymer/blend it could be concluded larger compression force produces harder tablets. When comparing hardness values in tablets composed of different polymer/blend and compressed with the same force it could be postulated that the hardness decreases in the following order HPMC K4M $>$ HPMC $15 \mathrm{M}>$ HPMC BLEND. The obtained values are expressed as mean value $\pm \mathrm{RSD}(\%)$ in Table 3.

Table 3. Tablet properties for batches 1/1, 1/2, 2/1, 2/2, 3/1, 3/2

\begin{tabular}{ccccccc}
\hline & P1/1 & P1/2 & P2/1 & P2/2 & P3/1 & P3/2 \\
\hline Mass & $392.32 \pm 0$. & 389.57 & 396.78 & $391.29 \pm 0$. & $401.26 \pm 0$. & $398.45 \pm 0.7$ \\
uniformity & 82 & \pm 0.84 & \pm 0.54 & 69 & 92 & 0 \\
Content (\%) & 99.34 & 100.21 & 102.75 & $102.34 \pm 0$. & $101.63 \pm 0$. & 100.95 \\
& \pm 0.47 & \pm 0.53 & \pm 0.77 & 28 & 67 & \pm 0.37 \\
Friability (\%) & 0.12 & & & 0.17 & 0.15 & \\
& \pm 0.03 & $0.14 \pm 0.06$ & $0.12 \pm 0.03$ & \pm 0.04 & \pm 0.05 & $0.18 \pm 0.04$ \\
Hardness (N) & $140.48 \pm 2$. & 128.12 & 136.26 & $118.01 \pm 4$. & $131.26 \pm 2$. & $111.83 \pm 5.5$ \\
& 93 & \pm 2.83 & \pm 2.45 & 90 & 62 & 3 \\
\hline
\end{tabular}

\section{Floating and swelling properties of the tablets}

From the obtained results for floating times it could be concluded that tablets containing HPMC polymer blend (Methocel K4M and Methocel K15M) had shortest FLT compared to tablets made by the same compression force which contained single polymer. There wasn't any significant difference in FLT between tablets composed of different single polymers made under same compression force. In terms of probes containing the same polymer which were made by different compression forces it could be noted that a slight difference in the FLT exists. Namely harder tablets tend to have longer floating lag time compared to softer tablets, which could be explained by the lower ability of water to penetrate and to hydrate the outer polymer layer and to provoque effervescent reaction which will provide floating of the dosage form. Concerning total floating time (TFT) all six probes remained buoyant over the media for periods longer than 8 hours. The complete results for FLT and TFT are given in Table 4.

Table 4. Results for in vitro buoyancy studies

\begin{tabular}{lllllll}
\hline & P1/1 & P1/2 & P2/1 & P2/2 & P3/1 & P3/2 \\
\hline Floating lag time (s) & 121.67 & 116.33 & 122.70 & 118.67 & 105.47 & 93.00 \\
$\begin{array}{l}\text { Total floating time } \\
\text { (s) }\end{array}$ & $>8$ & $>8$ & $>8$ & $>8$ & $>8$ & $>8$ \\
\hline
\end{tabular}


In terms of swelling index regarding tablets composed of the same polymer/blend but compressed with different forces, it could be concluded that softer tablets have higher swelling capability compared to harder tablets which could be due to the lower inter-particle connections in the tablets and higher porosity which lead to greater water uptake and greater and faster swelling degree of the matrix. Tablets containing HPMC K4M tend to swell less compared with the tablets containing polymer blend (intermediate swelling) and tablets composed of HPMC K15M which tend to have largest swelling index. This could be due to the highest solubility and erodability (due to low viscosity) of HPMC K4M in the media compared to the tablets containing polymer blend (intermediate viscosity) and tablets containing HPMC K15M which has highest viscosity and lowest solubility and erodability. Complete results of the swelling index of all six probes are given in Table 5.

Table 5. Swelling index (SI-\%) values

\begin{tabular}{lcccccc}
\hline & $\mathbf{p ~ 1 / 1}$ & $\mathbf{p ~ 1 / 2}$ & $\mathbf{p ~ 2 / 1}$ & $\mathbf{p 2 / 2}$ & $\mathbf{p ~ 3 / 1}$ & $\mathbf{p 3 / 2}$ \\
\hline SI after 1h & 52.17 & 60.55 & 79.29 & 87.05 & 85.46 & 88.41 \\
SI after 2h & 114.57 & 128.75 & 135.35 & 139.59 & 139.09 & 143.82 \\
SI after 3h & 163.68 & 175.82 & 198.73 & 206.59 & 182.45 & 197.22 \\
SI after 4h & 208.43 & 224.17 & 231.06 & 236.54 & 205.01 & 214.10 \\
SI after 5h & 227.87 & 243.25 & 256.31 & 274.36 & 255.39 & 269.52 \\
SI after 6h & 270.84 & 293.63 & 294.94 & 310.15 & 284.96 & 291.18 \\
SI after 7h & 301.79 & 316.53 & 349.24 & 364.72 & 318.74 & 328.71 \\
SI after 8h & 325.31 & 355.72 & 401.26 & 412.69 & 349.37 & 377.07
\end{tabular}

In vitro dissolution studies

All six probes of tablets formed a gel layer fast enough which give them firmness and provided controlled release of $t$ active compound in period of 8 hours by both diffusion through the pores of the hydrated polymer layer and erosion of the tablets surface. There are no significant differences into the dissolution profiles of tablets containing the same polymer/blend and compressed by different forces, nor of the tablets containing different polymers compressed by the same force. It could be concluded that all six probes are eligible for developing effervescent gastro-retentive controlled release matrix tablets. Results of drug released studies are calculated as mean value (\%) $\pm \mathrm{RSD}(\%)$ (Table 6) and are also shown as a cumulative curves on a plot (Figure 1).

Table 6. Dissolution profiles of examined tablets

\begin{tabular}{lllllll}
\hline & $\mathrm{P} 1 / 1$ & $\mathrm{P} 1 / 2$ & $\mathrm{P} 2 / 1$ & $\mathrm{P} 2 / 2$ & $\mathrm{P} 3 / 1$ & $\mathrm{P} 3 / 2$ \\
\hline after $1 \mathrm{~h}$ & $30.28 \pm 7.86$ & $27.69 \pm 0.84$ & $25.95 \pm 5.95$ & $26.05 \pm 5.79$ & $27.56 \pm 5.09$ & $27.61 \pm 1.27$ \\
after $2 \mathrm{~h}$ & $45.03 \pm 2.13$ & $45.29 \pm 3.92$ & $45.89 \pm 2.88$ & $42.45 \pm 2.35$ & $47.32 \pm 2.77$ & $44.86 \pm 1.75$ \\
after 4h & $67.2 \pm 0.85$ & $66.46 \pm 1.26$ & $66.74 \pm 4.55$ & $65.46 \pm 1.97$ & $69.25 \pm 0.96$ & $68.24 \pm 1.92$ \\
after 6h & $80.06 \pm 1.36$ & $81.73 \pm 2.17$ & $79.57 \pm 2.16$ & $80.53 \pm 2.07$ & $81.92 \pm 2.35$ & $80.75 \pm 1.87$ \\
after 8h & $89.1 \pm 3,66$ & $91.52 \pm 1.96$ & $88.06 \pm 4.41$ & $87.28 \pm 1.52$ & $91.73 \pm 2.12$ & $89.80 \pm 1.54$ \\
\hline
\end{tabular}




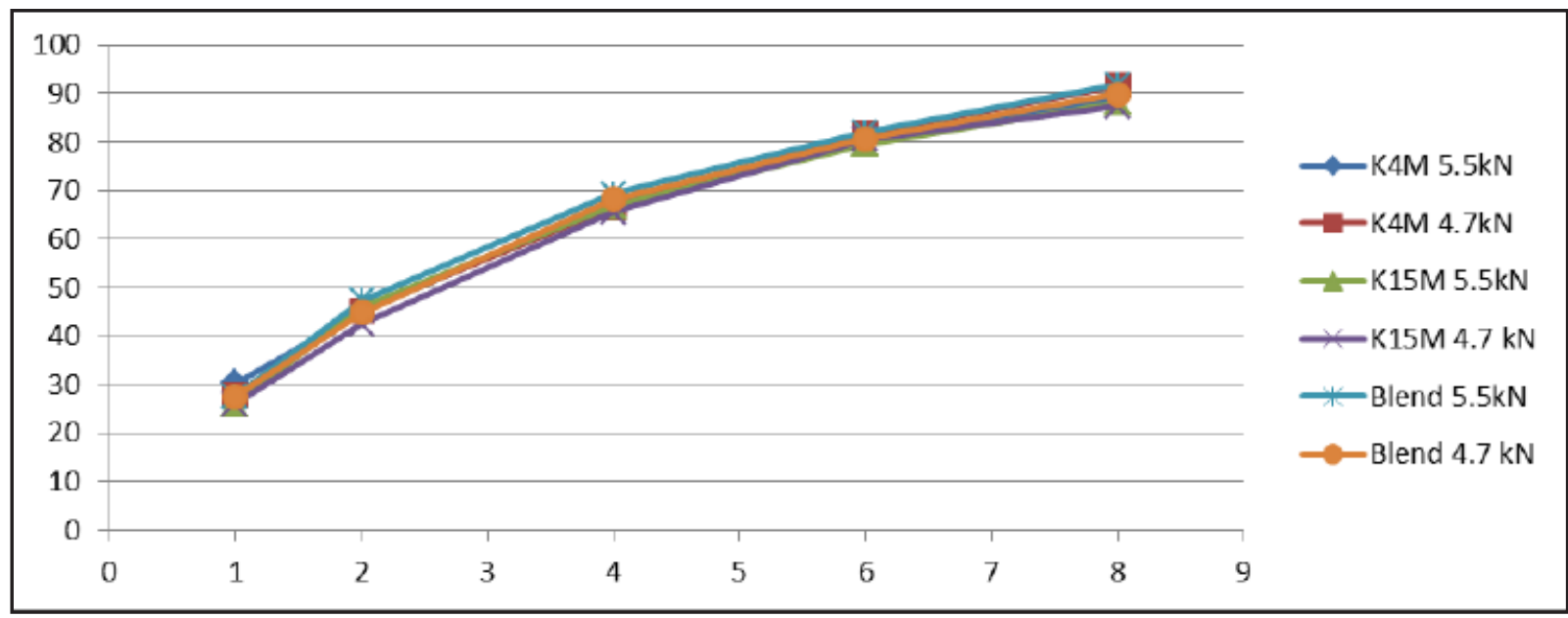

Figure 1. Cumulative release curves of all six probes (x axis- time (hours); $y$-axis drug released (\%)

\section{CONCLUSION}

Effervescent floating matrix tablets are promising approach in the development of targeted gastroretentive controlled release dosage forms, since they could be easy produced and easy administrated by the patients, and also they tend to have extended residence in the stomach area where they deliver the active compound in a controlled fashion over longer time periods. Rnitidine is one of the most used medicines in the present time, intended for treatment of different kind of GUT conditions such as peptic, gastric and duodenal ulcers, gastro-esophageal reflux disease, Zollinger-Ellison syndrome and corrosive esophageal disease. Due to its narrow absorption window ranitidine is a good candidate for developing gastro retentive dosage form. In our work we have successfully designed and produced gastro-retentive effervescent matrix tablets based on sodium bicarbonate and citric acid (effervescent compounds) and HPMC (polymer which control the release of the active compound). Two types of HPMC-s (HPMC K4M and HPMC K15M) and a 1:1 polymer mixture were used to produce three batch of tablets, and in every batch some amount of tablets were produced by compression force of $5.5 \mathrm{kN}$ and another amount were produced by $4.7 \mathrm{kN}$ (six probes were produced). From the obtained results it could be concluded that all powder mixtures intended for tableting showed fair flow properties and no flow aid addition was required. All six probes of tablets complied the pharmacopeial requirements concerning mass uniformity, content, hardness and friability. All six probes had short FLT, and remained buoyant over the gastric fluid for more than 8 hours. The used amount of 30\% polymer/ blend provided fast hydration and swelling of the outer matrix region which enabled continuous release of the drug compound through period of 8 hours and kept tablet integrity during that period. There were no significant differences in the release profile between probes containing different polymers and/or probes compressed with different forces, so it could be concluded that all six probes complied the requirements of our research.

\section{REFERENCES}

Aleksovski, A. (2012). Floating gastro-retentive dosage forms - a novel approach for targeted and controlled drug delivery, Human research in rehabilitation, 2 (1).

Aleksovski, A., Spaseska Aleksovska, E. and Jasic, M.
(2012). Formulation and evaluation of ascorbic acid extended release hydrophilic matrix tablets by using hydroxypropyl methylcellulose and polyethylene oxide as matrix forming polymers, Hrana u zdravlju i bolesti 2 (1). 
Aulton, M. (2007). Aulton's pharmaceutics- The design and manufacture of medicines, 3th edition. Elsevier, Edinburgh.

Dwivedi, S. and Kumar, V. (2011). Floating Drug Delivery systems - A Concept of Gastroretention Dosage Forms, International Journal of Research in Pharmaceutical and Biomedical Sciences, 2 (4).

Kumar, A., Rajesh, V., Suresh, P. and Anil, B. (2011). Overview of Gastro-Retentive Drug Delivery System. Journal of Natura Conscientia, 2 (3).

Qui, Y., Chen, Y., Zhang, G., Liu, L. and Porter, W. (2008).
Developing Solid Oral Dosage Forms: Pharmaceutical Theory \& Practice. Elsevier, New York.

Nirav S (2011). Formulation and evaluation of floating drug delivery systems. International Journal of Pharma and Bio Sciences, $2 / 1$.

Reynolds, J.E.F. (1996). Martindale The Extra Pharmacopoeia, the Royal Pharmaceutical Society, London.

Wen, H. and Park, K. (2010). Oral Controlled Release Formulation Design and Drug Delivery, Willey, New Jersey. Wilson, C.G. and Crowley, P.J. (2011). Controlled release in oral drug delivery, Springer, New York. 